\title{
Rationale and clinical benefits of an intensive long-term pulmonary rehabilitation program after oesophagectomy: preliminary report
}

\author{
Filippo Lococo ${ }^{1 *}$, Alfredo Cesario ${ }^{2}$, Silvia Sterzi ${ }^{3}$, Giovanni Magrone $^{3}$, Valentina Dall'Armi ${ }^{2}$, Francesca Mattei ${ }^{2}$, \\ Francesco Varone ${ }^{4}$, Venanzio Porziella', Stefano Margaritora ${ }^{1}$ and Pierluigi Granone ${ }^{1}$
}

\begin{abstract}
Patients who undergo oesophagectomy for oesophagealcancer (OC) usually have an overall poor prognosis and, still more preoccupying, an unsatisfactory quality of life (QoL). Considering that, as already noted, post-operative pulmonary function has a strong correlation with the long-term outcome and QoL after surgery, we have assumed and speculated on the clinical benefits of an intensive long-term pulmonary post-operative rehabilitation program in this particular subset of patients.

Herein, we report the preliminary results of a comparative retrospective analysis in a series of 58 patients who underwent radical oesophagectomy and post-operative chest physical therapy (CPT) under two different protocols, from October 2006 to January 2011.

Finally, we discuss on the time-trend analysis of pulmonary function and the potential role of post-operative pulmonary rehabilitation.
\end{abstract}

Keywords: Chest physical therapy, Oesophagectomy, Rehabilitation, Surgery

\section{Background}

In the last decades, quality of life (QoL) assessment is increasingly being used in clinical cancer research as an important outcome for assessing treatment effects [1]. In addition, recent attention has been directed toward the possibility of employing individual QoL assessments in daily clinical practice [2]. Both efforts are aimed at factoring QoL considerations explicitly into the medical decision-making process. Given that the patient is the most appropriate source of information on his QoL, such assessments are primarily derived from the patients themselves.

In this setting, we would like to discuss and speculate on the rehabilitation strategy in oesophageal cancer treatment. Recently, Verschuur and colleagues [3] reported their results on patients' physical fitness and the problems experienced, either physically or psychosocially, after oesophageal resection. Evidence has also been published suggesting that the impact of post-operative rehabilitation in patients

\footnotetext{
* Correspondence: filippo_lococo@yahoo.it

'Department of General Thoracic Surgery, Catholic University of the Sacred Heart, Largo F. Vito 1, Rome, Italy

Full list of author information is available at the end of the article
}

undergoing oesophagectomy is beneficial both in terms of long-term outcome [4] and QoL [5]. The conclusions of the analysis of a large series by Djärv are clear: "patients who do not recover physical function, pain, and fatigue scores within 6 months after potentially curative treatment for oesophageal cancer are at significant increased risk of shorter survival" [6], implying that the management of post-operative complications and the recovery of physical function after surgery are pivotal. Inspired by these considerations, in October 2006 we planned an experimental clinical trial on intensive long-term post-operative rehabilitation after oesophagectomy in our institution.

\section{Methods}

We retrospectively analyzed the data of 58 patients with oesophageal cancer (OC), consecutively observed and surgically treated in our department from October 2006 to January 2011, who received chest physical therapy (CPT) under two different protocols. Of these, 50 (Group A), treated from October 2006 to June 2010, underwent standard rehabilitative procedures (SR) and 8 (Group B), treated from June 2010 to January 2011, 
followed a new multimodal rehabilitation regimen based on intensive rehabilitative procedures (IR).

The SR consisted of coughing instruction, mainly to improve ventilation and promote expectoration. At the same time, patients were instructed to perform deep breathing and abdominal breathing as respiration training. General exercise therapy and a specific training session for the inspiratory muscles were also used to achieve early mobilization.

Regarding the IR, we adopted a multidisciplinary strategy along the lines of the protocol used for surgical Non Small Cell Lung Cancer (NSCLC) patients as described by Cesario et al. [7].

The Rehabilitation Team consisted of a chest physician director, physical therapists, nurses, a psychologist and a dietician. Subjects participated in 5 daily sessions each week, for a total of 4 weeks. The program included: (a) a supervised symptom-limited incremental exercise (cycloergometer test); (b) abdominal muscle activities, inspiratory resistive sessions, treadmill, upper and lower extremities training and full arm circling; c) educational sessions, conducted twice weekly, covering such topics as pulmonary physiopathology, pharmacology of patients' medications, dietary counselling, relaxation and stress management techniques, energy conservation principles, and breathing retraining.

Pulmonary function was evaluated before surgery $\left(\mathrm{T}_{0}\right)$ and 1 month after discharge $\left(\mathrm{T}_{2}\right)$ in both groups. In Group
A, the evaluation was performed after surgery and before IR $\left(\mathrm{T}_{1}\right)$. In addition, before and after IR all patients underwent specific measurements to evaluate the clinical benefit of the rehabilitation course: exercise endurance was evaluated with a 6-min walking distance (6MWD) test using the modified 6MWD protocol [8]; perceived breathlessness/ dyspnoea and leg fatigue were evaluated using the modified Borg scale [9]; perceived pain was estimated by a visual analogue scale (VAS) score [10]; general physical performance was tested by the Barthel score [11]. In addition, the multifactorial index, providing information on body mass, airflow obstruction, dyspnoea and exercise index (BODE index [12]), was also measured. Finally, the "Instrumental Activities of Daily Living" (IADL) score [13] was routinely administered before and after IR to check the general status of the patients and their ability to recover a "normal daily life".

Tests and treatment were performed as part of the clinical routine and were in accordance with the World Medical Association declaration of Helsinki [14]. Finally, an informed medical consent was also obtained from all patients enrolled in the present study.

\section{Results and discussion}

The main demographic and clinical characteristics of the study group are reported in Table 1. In particular, chronic obstructive pulmonary disease (COPD) was

Table 1 Clinical and demographic parameters of the study population

\begin{tabular}{|c|c|c|c|c|c|}
\hline \multirow[t]{2}{*}{ Variables } & \multicolumn{2}{|c|}{ Non Rehabilitated Group $(n=50)$} & \multicolumn{2}{|c|}{ Rehabilitated Group $(n=8)$} & \multirow[t]{2}{*}{ P-value } \\
\hline & \multicolumn{2}{|c|}{ n (\%) } & \multicolumn{2}{|c|}{ n (\%) } & \\
\hline Sex, F & \multicolumn{2}{|c|}{$16(32 \%)$} & \multicolumn{2}{|c|}{$2(25 \%)$} & 1.000 \\
\hline NAD & \multicolumn{2}{|c|}{$5(10 \%)$} & \multicolumn{2}{|c|}{$1(13 \%)$} & 1.000 \\
\hline Smoker & \multicolumn{2}{|c|}{$13(26 \%)$} & \multicolumn{2}{|c|}{$3(38 \%)$} & 0.672 \\
\hline Ex smoker & \multicolumn{2}{|c|}{$16(32 \%)$} & \multicolumn{2}{|c|}{$3(38 \%)$} & 1.000 \\
\hline Comorbility_pneumo & \multicolumn{2}{|c|}{$20(40 \%)$} & \multicolumn{2}{|c|}{$4(50 \%)$} & 0.706 \\
\hline Comorbility_other & \multicolumn{2}{|c|}{$18(36 \%)$} & \multicolumn{2}{|c|}{$1(13 \%)$} & 0.252 \\
\hline Operation type: Thoracotomy & \multicolumn{2}{|c|}{$16(32 \%)$} & \multicolumn{2}{|c|}{$3(38 \%)$} & 1.000 \\
\hline Transhiatal & \multicolumn{2}{|c|}{$34(68 \%)$} & \multicolumn{2}{|c|}{$5(63 \%)$} & \\
\hline Early_complications & \multicolumn{2}{|c|}{$21(42 \%)$} & \multicolumn{2}{|c|}{$3(38 \%)$} & 1.000 \\
\hline Early_complications_pneumo & \multicolumn{2}{|c|}{$13(26 \%)$} & \multicolumn{2}{|c|}{$2(25 \%)$} & 1.000 \\
\hline Late_complications & \multicolumn{2}{|c|}{$9(18 \%)$} & \multicolumn{2}{|c|}{$3(38 \%)$} & 0.342 \\
\hline Late_complications_pneumo & \multicolumn{2}{|c|}{$2(4 \%)$} & \multicolumn{2}{|c|}{$1(13 \%)$} & 0.365 \\
\hline $\mathrm{CT}$ & \multicolumn{2}{|c|}{$14(28 \%)$} & \multicolumn{2}{|c|}{$2(25 \%)$} & 1.000 \\
\hline \multirow[t]{2}{*}{ RT } & \multicolumn{2}{|c|}{$22(44 \%)$} & \multicolumn{2}{|c|}{$4(50 \%)$} & 1.000 \\
\hline & mean $\pm s d$ & median & mean $\pm s d$ & median & P-value \\
\hline Age & $67.46 \pm 0.53$ & 69.00 & $70.00 \pm 5.45$ & 69.5 & 0.5089 \\
\hline PY & $14.92 \pm 5.30$ & 10.00 & $20.38 \pm 5.71$ & 24.00 & 0.3418 \\
\hline BMl & $23.25 \pm 1.75$ & 23.00 & $22.64 \pm 0.94$ & 22.30 & 0.3356 \\
\hline Rehabilitation days & n.a. & n.a. & $15.13 \pm 3.60$ & 15.00 & n.a. \\
\hline
\end{tabular}


found in 20 patients of Group A (40\%) and 4 patients of Group B (50\%), respectively. The two study groups were comparable for demographic, pre-operative respiratory function and surgical characteristics, as well as for the peri-operative morbidity (42\% in Group A and 37.5\% in Group B; $\mathrm{p}=\mathrm{ns})$ and for pulmonary complications (25\% in Group A and 26\% in Group B; p =ns).

The results of pulmonary function tests and the timetrend analysis of these variables are illustrated in Table 2 and 3. As expected, almost all patients who underwent SR after surgery (Group A) showed a clear reduction of pulmonary function with a significant decrease in terms of FVC\%, $\mathrm{FEV}_{1} \%$, TLC\% and RV\% ( $\mathrm{p}<0.001$ in all cases).

On the other hand, a clinical benefit during the course of the IR in Group $B\left(\Delta \mathrm{T}_{1}-\mathrm{T}_{2}\right)$ was found in terms of $\mathrm{pO}_{2}$ [Mean $\Delta=8.9$ days; $\left.\mathrm{p}=0.0116\right]$, Borg-scale $[$ Mean $\Delta=1.5 ; \mathrm{p}=0.0083]$, Barthel Test $[$ Mean $\Delta=28.8$; $\mathrm{p}=0.0116], 6 \mathrm{MWD}[\mathrm{Mean} \Delta=70.4 ; \mathrm{p}=0.0117]$ and VASScore $[$ Mean $\Delta=4.18 ; \mathrm{p}=0.0115]$. An improvement was also found in pulmonary function, in terms of $\mathrm{FVC} \%$, $\mathrm{FEV}_{1} \%, \quad \mathrm{TLC} \% \quad(\mathrm{p}=0.0136, \quad \mathrm{p}=0.0136, \quad \mathrm{p}=0.0117$, respectively).

Therefore, the pulmonary function values after rehabilitation $\left(\mathrm{T}_{2}\right)$ were substantially similar when compared with pre-operative assessment $\left(\mathrm{T}_{0}\right)$ (Table 1$)$.

On the contrary, patients in Group A showed an incomplete functional recovery $\left(\Delta \mathrm{T}_{0}-\mathrm{T}_{2}\right)$ with the pulmonary function strongly decreased [FVC\% $(\mathrm{p}<0.0001$.$) ,$ $\mathrm{FEV}_{1} \%(\mathrm{p}<0.0001)$, TLC\% $\left.(\mathrm{p}<0.0001)\right]$. In fact, comparing the variation of pulmonary function values $\left(\Delta \mathrm{T}_{0}-\mathrm{T}_{2}\right)$ in the 2 groups, the data confirm that patients who underwent IR had a significantly lesser decrease in lung function (Table 1). This functional recovery [FVC\% $\quad \mathrm{p}=0.001 ; \quad \mathrm{FEV}_{1} \% \quad \mathrm{p}=0.0001 ; \quad \mathrm{TLC} \%$ $\mathrm{p}=0.0395$ ] is even more important if we consider the strong correlation with the long-term outcome and QoL of these patients, as already noted [15]. Finally, as reported in Table 2, the results of the IADL, measured before and after IR, demonstrated a slightly significant improvement $(\mathrm{p}=0.081)$ in daily living activities.

Patients who undergo oesophagectomy for OC usually have an overall poor prognosis and, even more so, an unsatisfactory QoL. In this setting, Djärv et al. [5] recently investigated the possible association between baseline Health-Related Quality of Life (HRQL) and survival, and also between changes in HRQL, before and after treatment, and survival in this particular subset of patients. As previously cited, the authors concluded that the risk of dying in patients with dyspnea is significatly higher when physical function, pain, and fatigue do not recover by 6 months from curative treatment.

Therefore, given that QoL is clearly associated with the short-time outcome of these patients, the achievement of a good physical function after surgery represents an enduring challenge for the multidisciplinary team dealing with the management of this disease. Generally, one of the most common pulmonary modifications related to this kind of surgery consists of a moderate-to-strong postoperative change in lung function (predominantly restrictive ventilator pattern) with decreases in vital capacity (VC) and functional residual capacity (FRC). The decrease in FRC impairs ventilation/perfusion matching and sometimes results in arterial hypoxemia [16]. Several pathophysiological mechanisms could be considered as a cause

Table 2 Time-trend analysis of pulmonary function in Group A (SR: Standard Rehabilitation) and Group B (IR: Intensive Rehabilitation)

\begin{tabular}{|c|c|c|c|c|c|c|c|c|c|c|}
\hline & \multirow[t]{2}{*}{ Variables } & \multicolumn{2}{|l|}{ TO } & \multicolumn{2}{|c|}{ T1 } & \multicolumn{2}{|c|}{$\mathrm{T} 2$} & \multirow{2}{*}{$\begin{array}{c}\text { P-value } \\
\text { T0-T1 }\end{array}$} & \multirow{2}{*}{$\begin{array}{c}\text { P-value } \\
\text { T1-T2 }\end{array}$} & \multirow{2}{*}{$\begin{array}{c}\text { P-value } \\
\text { T0-T2 }\end{array}$} \\
\hline & & mean $\pm s d$ & median & mean $\pm s d$ & median & mean \pm sd & median & & & \\
\hline \multirow[t]{4}{*}{ SR Group $(n=50)$} & FVC pred\% & $97.44 \pm 18.19$ & 96.5 & - & - & $85.21 \pm 20.03$ & 86.00 & - & - & $<0.0001$ \\
\hline & $\mathrm{FEV}_{1}$ pred $\%$ & $88.38 \pm 20.56$ & 91.5 & - & - & $77.19 \pm 21.73$ & 80.00 & - & - & $<0.0001$ \\
\hline & TLC pred\% & $95.32 \pm 16.66$ & 95.5 & - & - & $89.55 \pm 14.8$ & 88.00 & - & - & $<0.0001$ \\
\hline & RV pred\% & $104.46 \pm 28.18$ & 100.5 & - & - & $98.43 \pm 27.53$ & 94.00 & - & - & $<0.0001$ \\
\hline \multirow[t]{10}{*}{ IR Group $(n=8)$} & FVC pred\% & $96.75 \pm 13.61$ & 98.00 & $92.38 \pm 9.50$ & 93.50 & $95.88 \pm 8.39$ & 96.50 & 0.0925 & 0.0136 & 0.1797 \\
\hline & $\mathrm{FEV}_{1}$ pred $\%$ & $82.75 \pm 13.76$ & 79.50 & $78.50 \pm 9.90$ & 76.50 & $85.63 \pm 8.25$ & 81.50 & 0.0793 & 0.0136 & 0.5271 \\
\hline & TLC pred\% & $97.5 \pm 14.27$ & 100.50 & $87.25 \pm 10.40$ & 86.50 & $95.75 \pm 12.16$ & 96.50 & 0.0117 & 0.0117 & 0.1013 \\
\hline & RV pred\% & $107.00 \pm 18.94$ & 104.50 & $94.13 \pm 9.40$ & 91.50 & $102.88 \pm 15.43$ & 99.50 & 0.014 & 0.0138 & 0.0348 \\
\hline & 6MWD & - & - & $159.63 \pm 29.34$ & 152.50 & $223.63 \pm 33.81$ & 234.00 & - & 0.0117 & - \\
\hline & Borg & - & - & $4.25 \pm 0.71$ & 4.00 & $2.50 \pm 0.53$ & 2.50 & - & 0.0083 & - \\
\hline & Barthel & - & - & $67.13 \pm 4.7$ & 67.00 & $95.00 \pm 4.60$ & 95.50 & - & 0.0116 & - \\
\hline & Vas & - & - & $5.38 \pm 1.03$ & 5.00 & $1.20 \pm 0.64$ & 1.15 & - & 0.0115 & - \\
\hline & Po2 & & & $67.29 \pm 4.51$ & 67.85 & $78.45 \pm 5.26$ & 77.80 & - & 0.0116 & \\
\hline & IADL Score & & & $2,7 \pm 0.43$ & 3.00 & $4.2 \pm 0.79$ & 5.00 & - & 0.081 & \\
\hline
\end{tabular}




\begin{tabular}{|c|c|c|c|c|c|c|c|c|c|c|c|}
\hline \multirow[t]{2}{*}{ Group } & \multirow[t]{2}{*}{ Variables } & \multicolumn{3}{|c|}{ Thoracotomy } & \multicolumn{3}{|c|}{ Transhiatal } & \multicolumn{4}{|c|}{ Total } \\
\hline & & $n$ & mean $\pm s d$ & median & $n$ & mean $\pm s d$ & median & $n$ & mean $\pm s d$ & median & P-value \\
\hline $\mathrm{IR}$ & Delta T0-T2FVC pred. \% & 3 & $-1.71 \pm 1.18$ & -1.16 & 5 & $-1.11 \pm 12.80$ & -1.15 & 8 & $-0.05 \pm 9.81$ & -1.16 & 0.001 \\
\hline SR & & 15 & $-20.68 \pm 11.80$ & -21.28 & 32 & $-8.53 \pm 5.77$ & -6.42 & 50 & $-12.40 \pm 9.88$ & -9.32 & \\
\hline $\mathbb{R}$ & Delta T0-T2FEV1 pred. \% & 3 & $-2.14 \pm 5.42$ & -3.74 & 5 & $-9.04 \pm 12.44$ & -3.85 & 8 & $-4.83 \pm 11.41$ & -1.92 & 0.0001 \\
\hline$S R$ & & 15 & $-21.28 \pm 11.32$ & -22.22 & 32 & $-8.33 \pm 6.06$ & -7.69 & 50 & $-12.46 \pm 10.05$ & -8.62 & \\
\hline $\mathbb{R}$ & Delta T0-T2TLC pred. \% & 3 & $-1.56 \pm 1.43$ & -1.92 & 5 & $-1.48 \pm 3.47$ & -3.00 & 8 & $-1.52 \pm 2.73$ & -2.36 & 0.0395 \\
\hline SR & & 15 & $-7.23 \pm 6.84$ & -7.07 & 32 & $-4.67 \pm 4.32$ & -5.16 & 50 & $-5.49 \pm 5.32$ & -5.19 & \\
\hline $\mathbb{R}$ & Delta T0-T2RV pred. \% & 3 & $-3.03 \pm 2.68$ & -4.00 & 5 & $-3.70 \pm 3.51$ & -5.50 & 8 & $-3.44 \pm 3.03$ & -4.54 & 0.8109 \\
\hline$S R$ & & 15 & $-6.82 \pm 6.33$ & -3.90 & 32 & $-4.11 \pm 5.36$ & -2.54 & 50 & $-4.98 \pm 5.76$ & -3.64 & \\
\hline
\end{tabular}

of this dysfunction. Firstly, there is an inadequate pain control post-thoracotomy; in fact, a postero-lateral thoracotomy is among the most painful of surgical incisions because major muscles, including the nerves, are divided, and the ribs are distracted and partly or wholly removed. The decrease in respiratory function can last for some weeks, and this is amplified in patients with respiratory disease [17]. Moreover, thoracic incisions strongly affect the integrity of the respiratory muscles, resulting in pulmonary dysfunction and, consequently, in a change in the quality of breathing. In this context, considering the association between the post-operative pulmonary function and the post-operative QoL, as suggested by several authors $[17,18]$, we hypothesized that the recovery of a normal lung capacity after surgery (as soon as possible, and in the best possible way) represents a factor of great importance for the overall strategy of care of the OC.

\section{Strengths and limitations}

This paper has the usual limitations associated with retrospective mono-centric studies: the long duration of patient recruitment and the limited number of patients. Given that this is a preliminary report of a retrospective comparative analysis of two different "strategies of care" in the post-operative management of patients who underwent oesophagectomy, the number of patients in the two groups is disparate: this represents a further limitation ("intrinsic bias") that readers should clearly keep in mind.

Moreover, we did not perform a direct evaluation of the QoL score of the patients because no specific and validated questionnaires such as EORTC QLQ-C30 [19] were administered during the study period, since the analysis focused mainly on post-operative pulmonary functional values. In any case, the IADL score was administered in all patients who underwent the rehabilitation program and it can be considered as a surrogate method (indirect evaluation) to gain some information on QoL, as already validated by previous experiences [20-22].
Despite all the limitations mentioned above, this study has the merit of highlighting the critical role of a multidisciplinary post-operative management of patients who have undergone oesophagectomy, and suggests that, in such patients, the respiratory function and exercise capacity significantly improve after an intensive outpatient long-term (4-week) pulmonary rehabilitation program. Inspired by these preliminary results, we have planned a prospective randomised controlled trial. In this ongoing trial the positive results described in this study will be verified along with a proper QoL evaluation using specific and widely accepted scoring systems.

\section{Conclusions}

As previously suggested, post-operative rehabilitation in patients undergoing oesophagectomy is beneficial both in terms of long-term outcome [4] and QoL [5]. According to our preliminary experience, a multimodal outpatient long-term rehabilitation program could be considered as a key component of the management of this subset of patients, providing clinical benefits and a potential improvement in QoL.

However, the validation of this approach and its translation into everyday clinical practice require further investigation.

\footnotetext{
Abbreviations

BMI: Body Mass Index; BODE: Body mass, airflow Obstruction, Dyspnoea and Exercise; COPD: Chronic Obstructive Pulmonary Disease; CPT: Chest Physical Therapy; CT: Chemotherapy; EORTC QLQ-C30: European Organization for Research and Treatment of Cancer Questionnaire for the Quality of Life composed of 30 Core questions; FEV1\%: Forced Expiratory Volume in 1 second (percentage of the theoretical value); FRC: Functional Residual Capacity; FVC\%: Forced Vital Capacity (percentage of the theoretical value); HRQL: Health-Related Quality of Life; IADL: Instrumental Activities of Daily Living; IR: Intensive Rehabilitative procedures; NAD: Neoadjuvant Therapy; NSCLC: Non Small Cell Lung Cancer; OC: Oesophageal Cancer; pO2: Oxygen Pressure; PY: Pack/years Index; QoL: Quality of Life; RT: Radiotherapy; SR: Standard Rehabilitative procedures; $T_{0}$ : before surgery; $T_{1}$ : after surgery and before IR; $T_{2}: 1$ month after the discharge; TLC\%: Total Lung Capacity (percentage of the theoretical value); VAS: visual analogue scale; VC: Vital Capacity; $\Delta$ : Delta o Differenza; 6MWD: 6-min Walking Distance test.
} 


\section{Competing interests}

The authors declare that they have no competing interests.

\section{Author details}

'Department of General Thoracic Surgery, Catholic University of the Sacred Heart, Largo F. Vito 1, Rome, Italy. ${ }^{2}$ Unit of Clinical and Molecular Epidemiology, IRCCS San Raffaele Pisana, Rome, Italy. ${ }^{3}$ Department of Physical Rehabilitation Medicine, Campus Bio-Medico, Rome, Italy.

${ }^{4}$ Department of Pulmonary Medicine, Catholic University of the Sacred Heart, Largo F. Vito 1, Rome, Italy.

Received: 18 July 2012 Accepted: 18 July 2012

Published: 28 July 2012

\section{References}

1. Sneeuw KC, Aaronson NK, Sprangers MA, Detmar SB, Wever LD, Schornagel JH: Evaluating the quality of life of cancer patients: assessments by patients, significant others, physicians and nurses. Br J Cancer 1999, 81:87-94.

2. Sprangers MA, Aaronson NK: The role of health care providers and significant others in evaluating the quality of life of patients with chronic disease: a review. J Clin Epidemiol 1992, 45:743-760.

3. Verschuur EM, Steyerberg EW, Kuipers EJ, Essink-Bot ML, Tran KT, Van Der Gaast A, Tilanus HW, Siersema PD: Experiences and expectations of patients after oesophageal cancer surgery: an explorative study. Eur J Cancer Care (Engl) 2006, 15:324-332.

4. Kinugasa S, Tachibana M, Yoshimura H, Ueda S, Fujii T, Dhar DK, Nakamoto T, Nagasue N: Postoperative pulmonary complications are associated with worse short-and long-term outcomes after extended esophagectomy. J Surg Oncol 2004, 88:71-77.

5. Djärv T, Blazeby JM, Lagergren P: Predictors of postoperative quality of life after esophagectomy for cancer. J Clin Oncol 2009, 27:1963-1968.

6. Djärv T, Metcalfe C, Avery KN, Lagergren P, Blazeby JM: Prognostic value of changes in health-related quality of life scores during curative treatment for esophagogastric cancer. J Clin Oncol 2010, 28:1666-1670

7. Cesario A, Ferri L, Galetta D, Pasqua F, Bonassi S, Clini E, Biscione G, Cardaci V, Di Toro S, Zarzana A, Margaritora S, Piraino A, Russo P, Sterzi S, Granone P: Post-operative respiratory rehabilitation after lung resection for non-small cell lung cancer. Lung Cancer 2007, 57:175-180.

8. Steele B: Timed walking tests of exercise capacity in chronic cardiopulmonary illness. J Cardiopulm Rehabil 1996, 16:25-33.

9. Borg GA: Psychophysical bases of perceived exertion. Med Sci Sports Exerc 1982, 14:377-381.

10. Wewers ME, Lowe NK: A critical review of visual analogue scales in the measurement of clinical phenomena. Res Nurs Health 1990, 13:227-236

11. Sullivan O, Susan B, Schmitz, Thomas J: Physical Rehabilitation. Philadelphia, PA: FA Davis Company; 2007:385.

12. Celli BR, Cote CG, Marin JM, Casanova C, Montes de Oca M, Mendez RA, Pinto Plata V, Cabral HJ: The body-mass index, airflow obstruction, dyspnea, and exercise capacity index in chronic obstructive pulmonary disease. N Engl J Med 2004, 350:1005-1012.

13. Lawton MP, Brody EM: Assessment of older people: self-maintaining and instrumental activities of daily living. Gerontologist 1969, 9:179-186.

14. World Medical Association Declaration of Helsinki: Ethical principles for medical research involving human subjects. JAMA 2000, 284:3043-3045.

15. Ali J, Weisel RD, Layug AB, Kripke BJ, Hechtman HB: Consequences of postoperative alterations in respiratory mechanics. Am J Surg 1974, 128:376-382.

16. Chetta A, Tzani P, Marangio E, Carbognani P, Bobbio A, Olivieri D: Respiratory effects of surgery and pulmonary function testing in the preoperative evaluation. Acta Biomed 2006, 77:69-74.

17. Moy ML, Ingenito EP, Mentzer SJ, Evans RB, Reilly JJ Jr: Health-related quality of life improves following pulmonary rehabilitation and lung volume reduction surgery. Chest 1999, 115:383-389.

18. Granger CL, McDonald CF, Berney S, Chao C, Denehy L: Exercise intervention to improve exercise capacity and health related quality of life for patients with Non-small cell lung cancer: a systematic review. Lung Cancer 2011, 72:139-153.

19. Benson K, Hartz AJ: A comparison of observational studies and randomized, controlled trials. N Engl J Med 2000, 342:1878-1886.
20. Maione P, Perrone F, Gallo C, Manzione L, et al: Pretreatment quality of life and functional status assessment significantly predict survival of elderly patients with advanced non-small-cell lung cancer receiving chemotherapy: a prognostic analysis of the multicenter Italian lung cancer in the elderly study. J Clin Oncol 2005, 23:6865-6872.

21. Huang YH, Wu CY, Hsieh YW, Lin KC: Predictors of change in quality of life after distributed constraint-induced therapy in patients with chronic stroke. Neurorehabil Neural Repair 2010, 24:559-566.

22. Goverover Y, Chiaravalloti N, Gaudino-Goering E, Moore N, DeLuca J: The relationship among performance of instrumental activities of daily living, self-report of quality of life, and self-awareness of functional status in individuals with multiple sclerosis. Rehabil Psychol 2009, 54:60-68.

doi:10.1186/2049-6958-7-21

Cite this article as: Lococo et al:: Rationale and clinical benefits of an intensive long-term pulmonary rehabilitation program after oesophagectomy: preliminary report. Multidisciplinary Respiratory Medicine 2012 7:21.

\section{Submit your next manuscript to BioMed Central and take full advantage of:}

- Convenient online submission

- Thorough peer review

- No space constraints or color figure charges

- Immediate publication on acceptance

- Inclusion in PubMed, CAS, Scopus and Google Scholar

- Research which is freely available for redistribution 